\title{
PENGEMBANGAN OBJEK WISATA LEMBAH HARAU KABUPATEN LIMA PULUH KOTA
}

\author{
Ravi Suryadinata ${ }^{1}$, Rahmanelli $^{2}$, \\ Program Studi Pendidikan Geografi, \\ Fakultas Ilmu Sosial, Universitas Negeri Padang \\ e_mail: sanditaravi@gmail.com
}

\begin{abstract}
ABSTRAK
Penelitian ini bertujuan untuk mendeskripsikan tentang kekuatan, kelemahan, peluang dan ancaman serta kelayakan pengembangan objek wisata Lembah Harau Kabupaten Lima Puluh Kota. Jenis penelitian ini adalah deskriptif dengan pendekatan kuantatif. Subjek penelitian ditentukan dengan purposive sampling. Subjek penelitian adalah Dinas Pariwisata, Pemuda, dan Olahraga Kabupaten Lima Puluh Kota, pengunjung objek wisata Lembah Harau dan masyarakat Lembah Harau. Teknik pengumpulan data dalam penelitian ini adalah melalui observasi, kuisioner dan dokumentasi. Teknik analisa data yang digunakan yaitu teknik reduksi data, display data, penarikan kesimpulan dan analisis SWOT disertai AHP. Hasil penelitian mengungkapkan: 1) Faktor kekuatan yang menjadi prioritas adalah meningkatkan daya tarik objek wisata. 2) Faktor kelemahan yang menjadi prioritas adalah mengatasi tempat-tempat tersembunyi yang dikhawatirkan akan digunakan untuk hal-hal yang negatif dari warga setempat maupun dari pengunjung. 3) Faktor peluang yang menjadi prioritas adalah menggerakkan sektor perekonomian masyarakat. 4) Faktor ancaman yang menjadi prioritas untuk dicegah adalah ketidakstabilan ekonomi akibat kondisi pariwisata yang fluktuatif. 5) Dalam kuadran SWOT menunjukkan bahwa wisata Lembah Harau berada pada kuadran 1 dengan skor faktor internal 0,28 dan skor faktor eksternal 0,382 yang berarti objek wisata Lembah Harau layak untuk dikembangkan.
\end{abstract}

\section{Kata kunci: Pengembangan, Kelayakan, Objek Wisata Alam, Lembah Harau.}

\begin{abstract}
This study aims to obtain and describe the strengths, weaknesses, opportunities, threats and advisability development of Lembah Harau Tourism District of Lima Puluh Kota. The type of this research is descriptive with quantitative approach. Subject in this research determined by purposive sampling. Research subject are Department of Tourism, Youth, and Sports District of Lima Puluh Kota, tourist and local community of Lembah Harau. Techniques data collected through observation, questionnaires and documentation. Analysis data technique used reduction techniques, display data, drawing conclusions data and SWOT analysis with AHP. The results showed that: 1) The strength factor that become a priority is increase the attraction of tourist attraction. 2) The weakness factor that become a priority is overcome the hidden places that feared will be used for negative things from local communinty as well as from tourist. 3) The opportunity factor that becomes a priority is mobilize the economic sector of locals. 4) The threat factors that become avoid to priority is unstabilished economy cause of fluctuative tourism condition. 5) SWOT quadrant shows that Lembah Harau tourism in quadrant 1 with internal factor score 0,28 and external factor score 0,382 which means Lembah Harau tourism is feasible to be developed.
\end{abstract}

Keywords: Development, Advisability, Natural Tourism Object, Lembah Harau.

\footnotetext{
${ }^{1}$ Mahasiswa Program Studi Pendidikan Geografi, Jurusan Geografi, Fakultas Ilmu Sosial, Universitas Negeri Padang.

${ }^{2}$ Dosen Jurusan Geografi, Fakultas Ilmu Sosial, Universitas Negeri Padang. Pembimbing 1, Dra. Rahmanelli, M.Pd. Pembimbing
} 


\section{PENDAHULUAN}

Pariwisata adalah salah satu industri terbesar dunia yang berada di berbagai negara. Pariwisata dapat meningkatkan pemasukan keuangan negara. Semakin banyak objek wisata yang berkualitas di suatu negara maka negara tersebut akan semakin maju. Ada beberapa sebab manusia melakukan perjalanan. Ada yang melakukan perjalanan karena sebab-sebab yang erat berkaitan dengan eksistensi dan keselamatan hidup manusia. Misalnya untuk melarikan diri dari bencana alam, peperangan dan musibah lainnya, namun begitu hubungan yang ditimbulkan oleh perjalanan manusia diluar tempat tinggalnya adalah fenomena pariwisata (Kodhyat, 1996: $3)$.

Indonesia mempunyai kekayaan alam yang berlimpah serta pemandangan alam yang indah dan nyaman, lingkungan hidup yang segar serta kebudayaan yang beraneka ragam merupakan sumber yang potensial bagi pengembangan industri pariwisata. Usaha yang perlu dilakukan dalam pengembangan pariwisata adalah mengetahui baik atau tidaknya suatu daerah untuk dikembangkan menjadi kawasan wisata. Kita harus terlebih dahulu mengetahui faktor-faktor yang sangat menentukan bagi pengembangan wisata yaitu adanya kebebasan bergerak dalam arti melakukan perjalanan, kelengkapan sarana transportasi dan komunikasi, adanya daya tarik didaerah tujuan wisata (DTW), terjaminnya keamanan, serta memadainya pelayanan dan informasi di objek wisata. Pariwisata juga sebagai industri nasional yang secara bersama menghasilkan barang-barang dan jasa yang dibutuhkan wisatawan pada khususnya. Industri pariwisata di Indonesia bersifat suatu usaha pengembangan dan pembangunan serta kesehjateraan masyarakat dan Negara (Yoeti, 1996:151).

Pengembangan objek wisata adalah suatu proses yang berkesinambungan untuk melakukan perubahan dan pengelolaan potensi pariwisata yang memiliki makna upaya untuk lebih meningkatkan sumber daya yang dimiliki oleh suatu objek wisata dengan cara melakukan pembangunan unsur-unsur fisik maupun non fisik dari sistem pariwisata sehingga dapat meningkatkan produktivitas. Pengembangan dapat didefinisikan sebagai suatu proses untuk merujuk pada perubahan yang lebih baik dari sebelumnya. Menurut Suwantoro (2004:19), Unsur pokok yang harus mendapat perhatian guna menunjang pengembangan pariwisata di daerah tujuan wisata yang menyangkut pada perencanaan, pelaksanaan pembangunan, dan pengembangannya meliputi 5 unsur, yaitu: Objek dan daya tarik wisata, prasarana wisata, sarana wisata, tata laksana atau infrastruktur, masyarakat dan lingkungan.

Provinsi Sumatera Barat merupakan salah satu daerah tujuan wisata yang menjadi andalan Indonesia. Daya tarik wisata Sumatera Barat terdapat pada objek wisata alam, objek wisata budaya, dan objek wisata olahraga atau hobi. Sumatera Barat memiliki hampir semua jenis objek wisata alam seperti laut, pantai, danau, 
gunung dan ngarai. Untuk melengkapi fasilitas pariwisata, pemerintah juga menyediakan sarana penunjang seperti kereta api wisata yang beroperasi pada jam-jam tertentu dihari libur.

Kabupaten Lima Puluh Kota merupakan kabupaten yang berada di dalam Pemerintahan Provinsi Sumatera Barat yang mencoba mengembangkan potensi wisata yang dimilikinya, baik wisata alam, wisata budaya, dan wisata sejarah. Objek wisata yang berada di Kabupaten Lima Puluh Kota memiliki keuntungan yang sangat besar baik bagi pemerintah maupun masyarakat, sebagai penambah devisa dan penggerak perekonomian serta promosi hasil-hasil industri pariwisata masyarakat. Salah satu daerah tujuan wisata di Kabupaten Lima Puluh Kota adalah Lembah Harau, yang berada, berjarak kurang lebih 176 kilo meter atau empat jam perjalanan dari ibukota Provinsi Sumatera Barat.

Lembah harau adalah salah satu wisata alam yang indah dan cukup mengagumkan dengan bukit-bukit kecil, bentangan sawah, air terjun, sungai, tebing dan pemandian alam. Lembah ini terletak diantara dua bukit yaitu Bukit Jambu dan Bukit Rengkok. Mempunyai empat air terjun dengan jarak 17 kilo meter dari kota Payakumbuh. Lembah ini merupakan salah satu kenampakan alam yang unik atau khusus untuk Sumatera Barat. Keempat air terjun itu adalah Air Terjun Bunta, Sarah Ngurai, Sarasah dan Barayun.

Berdasarkan observasi awal objek wisata ini belum didukung oleh sarana dan prasarana yang memadai seperti pengelolaan sampah, arena bermain, sarana yang masih kurang seperti tempat ibadah, toilet dan fasilitas tempat bersantai yang masih kurang yaitu tempat duduk dan meja, begitu pula dengan warung-warung kecil yang masih kurang berkualitas disebabkan karena kurangnya kebersihan pada warung itu sendiri, fasilitas warung yang belum bagus dan menu makanan yang kurang bervariasi.

Objek wisata Lembah Harau juga memiliki kekuatan, kelemahan, peluang dan ancaman yang sudah diobservasi melalui pertanyaan-pertanyaan yang ditujukan kepada pengunjung dan masyarakat. Kekuatan yang terdapat di Lembah Harau diantaranya adalah lokasi yang strategis, objek wisata yang menarik, masyarakat yang ramah dan terbuka, memiliki atraksi alam dan buatan, kondisi jalan menuju objek wisata tergolong baik, serta udara yang sejuk. Namun disamping kekuatan yang ada pada Lembah Harau, objek wisata ini juga memiliki kelemahan yakni, akses masuk dan keluar hanya terdapat satu jalur, jalan antar objek wisata yang tergolong kecil atau sempit, jarak antar objek wisata yang terlalu jauh, informasi, komunikasi dan promosi yang lemah, banyak tempat tersembunyi untuk melakukan hal-hal yang negatif, serta kuliner khas Kabupaten Lima Puluh Kota yang kurang ditonjolkan. Walaupun demikian objek wisata Lembah Harau berpeluang untuk meningkatkan PAD Kabupaten Lima Puluh Kota, menggerakkan sektor perekonomian masyarakat, munculnya kuliner khas Kabupaten Lima Puluh Kota, tumbuh dan berkembangnya 
industri kepariwisataan, dapat mengembangkan atraksi yang berkaitan dengan alam, serta meningkatnya eksistensi pariwisata Kabupaten Lima Puluh Kota. Disamping peluang yang cukup menjanjikan Lembah Harau memiliki ancaman yang sangat mengkhawatirkan diantaranya yitu, tidak terkendalinya objek wisata Lembah Harau Kabupaten Lima Puluh Kota, hilangnya kuliner khas Kabupaten Lima Puluh Kota karena masuknya makanan asing, pernah terjadi banjir dan orang hilang, pernah terjadinya perilaku asusila antar muda-mudi, dapat memicu pemalakan dari pendatang atau warga setempat, serta dikhawatirkan terjadi kecelakaan karna kondisi jalan yang sempit.

Jika masalah ini masih tetap dibiarkan, maka akan menyebabkan menurunnya pengembangan objek wisata Lembah Harau dan dikhawatirkan akan berdampak pada penurunan pengunjung.

\section{METODE PENELITIAN}

\section{Jenis Penelitian}

Jenis penelitian ini adalah penelitian deskriptif dengan pendekatan kuantitatif. Penelitian ini berlokasi di objek wisata Lembah Harau Kabupaten Lima Puluh Kota. Penelitian ini berlokasi di Lembah Harau Kabupaten Lima Puluh Kota. Penelitian dilakukan pada bulan Mei 2017 sampai dengan bulan Agustus 2017.

\section{Subjek Penelitian}

Penulis menentukan subjek penelitian dengan teknik "Purposive Sampling" yaitu subjek penelitian ditentukan berdasarkan pertimbangan tertentu. Pertimbangan tertentu ini, misalnya orang tersebut yang dianggap paling tahu tentang apa yang kita harapkan atau mungkin dia sebagai penguasa sehingga memudahkan peneliti menjelajahi objek/situasi sosial yang diteliti (Sugiyono, 2012:53).

\section{Teknik Pengumpulan Data}

Dalam pengumpulan data, penulis menggunakan teknik observasi, kuisioner dan dokumentasi.

\section{Sumber Data}

Penelitian ini berusaha untuk mengumpulkan data dengan cara menggunakan data primer dan data sekunder.

Data primer yaitu data yang diperoleh melalui observasi dan kuisioner dengan subjek penelitian. Data primer dalam penelitian ini diperoleh melalui observasi masingmasing objek wisata yang terdapat pada Lembah Harau guna mendapatkan faktor-faktor pengembangan objek wisata, meliputi faktor kekuatan, kelemahan, peluang dan ancaman.

Data sekunder diperoleh melalui buku-buku perpustakaan pusat UNP, Badan Pusat Statistik Lima Puluh Kota, Dinas Kebudayaan Pariwisata Pemuda dan Olahraga Kabupaten Lima Puluh Kota dan POKJA AMPL Kabupaten Lima Puluh Kota.

\section{Tahap-Tahap Penelitian}

Tahap-tahap pada penelitian ini berdasarkan sesuai dengan Moleong (2002) yaitu, tahap pra lapangan meliputi: (1) memilih lapangan/lokasi penelitian yang berada di Lembah Harau Kabupaten Lima Puluh Kota, (2) mengurus perizinan ke Badan Tata Usaha FIS dan Badan Kestuan Bangsa 
dan Politik Kabupaten Lima Puluh Kota, (3) menjajaki daerah penelitian dititik-titik tertentu objek wisata Lembah Harau yang ramai dikunjungi oleh wisatawan, (4) memilih dan memanfaatkan subjek penelitian yaitu kepala bidang pariwisata, kasi pengembangan dan pengelolaan pariwisata, staff seksi pengembangan dan pengelolaan destinasi pariwisata, kasi promosi dan informasi pariwisata serta pengunjung dan masyarakat atau pihak lain yang dapat memberikan informasi, (5) menyiapkan perlengkapan penelitian berupa angket dan buku kecil untuk mencatat informasi, tahap pekerjaan lapangan meliputi (1) memahami latar penelitian dan persiapan diri. Seorang peneliti hendaknya memiliki keyakinan terhadap hal yang akan ditelitinya. Peneliti harus mampu menguasai lapangan dan mampu mempersiapkan diri ketika akan mengadakan penelitian, (2) memasuki lapangan, ketika peneliti berada di lapangan maka dituntut sebuah kemandirian dan kemampuan dalam menjalankan penelitian agar tujuan dalam meneliti lebih terarah dan benar sesuai dengan prosedur yang ada (3) berperan serta sambil mengumpulkan data agar penelitian lebih terarah, maka sebaiknya seorang peneliti mampu mempunyai peran dalam penelitian yang dilakukannya dan tahap analisis data meliputi (1) konsep dasar analisis data, merupakan pekerjaan menganalisis data dalam hal mengatur, mengurutkan, mengelompokkan, memberikan kode dan mengkategorikan data, (2) memberikan penafsiran data, merupakan pekerjaan menguraikan serta menginterpretasikan data, dan (3) menemukan pencatatan dan analisis data, merupakan tahap dengan melakukan pencatatan serta memahami data secara keseluruhan.

\section{Teknik Analisis Data}

Metode penelitian ini menggunakan penggabungan antara analisis SWOT dan AHP. Komponen yang dianalisis adalah kekuatan, kelemahan, peluang dan ancaman yang ada pada objek wisata Lembah Harau untuk menentukan yang menjadi prioritas dalam komponen tersebut, menentukan kelayakan pengembangan objek wisata Lembah Harau dan merumuskan pengembangan objek wisata Lembah Harau.

a. Analisis Potensi Objek Wisata

Objek dan daya tarik (flora, fauna, dan objek lainnya) yang telah diperoleh kemudian dianalisis sesuai dengan kriteria penskoringan pada Pedoman Analisis Daerah Operasi Objek dan Daya Tarik Wisata Alam Dirjen PHKA tahun 2003 sesuai dengan nilai yang telah ditentukan untuk masing-masing kriteria. Jumlah nilai untuk satu kriteria penilaian ODTWA dapat dihitung dengan mengkalikan jumlah nilai unsur-unsur pada kriteria dengan bobot nilai untuk mendapatkan skor/nilai suatu kriteria. Jumlah nilai untuk satu kriteria penilaian ODTWA dapat dihitung dengan persamaan sebagai berikut:

$$
S=N \times B
$$


Ket: $S=$ skor/nilai suatu kriteria

$N=$ jumlah nilai unsur-unsur pada kriteria

$B=$ bobot nilai

b. Penghitungan Bobot Analisis SWOT dengan AHP

Dalam penelitian ini pembobotan variabel-variabel penentu pengembangan objek wisata Lembah Harau Kabupaten Lima Puluh Kota menggunakan AHP yang berdasarkan pada persepsi subjek penelitian. Dalam menggunakan metode AHP ada beberapa tahap yang dipergunakan. Tahap awal adalah merekapitulasi jawaban kuisioner kemudian membuat tabulasi data dengan bantuan excel. Hasil tabulasi data tersebut dicari nilai rata-rata seluruh jawaban. Setelah rata-rata jawaban diketahui langkah selanjutnya adalah membuat matrik perbandingan berpasangan untuk memperoleh tingkat kepentingan variabel.

Selanjutnya menghitung Priority Vector dengan cara membandingkan masing-masing nilai dengan jumlah kolomnya kemudian mengambil nilai rata-rata baris dari bobot relatif secara keseluruhan, selanjutnya menghitung rasio konsistensi untuk memeriksa apakah penilaian perbandingan berpasangan telah dilakukan dengan konsisten atau tidak yang menggunakan software expert choice yang sudah berdasarkan dalam ketentuan skala saaty. (Saaty: 1993)
Tabel 1. Uraian Faktor SWOT dengan Skala Saaty

\begin{tabular}{|c|c|c|c|c|c|c|c|}
\hline \multirow{7}{*}{ Bagian } & \multicolumn{7}{|c|}{ B } \\
\hline \multirow{7}{*}{ A } & $\begin{array}{c}\text { Faktor } \\
\text { SWOT }\end{array}$ & a & b & c & d & e & f \\
\hline & a & & & & & & \\
\hline & b & & & & & & \\
\hline & c & & & & & & \\
\hline & d & & & & & & \\
\hline & e & & & & & & \\
\hline & f & & & & & & \\
\hline
\end{tabular}

c. Analisis Strategi Pengembangan dengan Matriks SWOT

Bobot diberi nilai mulai dari 1 (sangat penting) sampai dengan 0 (tidak penting). Bobot dari masingmasing faktor strategis harus berjumlah 1. Rating untuk kekuatan dan peluang diberi skala mulai dari 4 (sangat besar), 3 (besar), 2 (kecil), dan 1 (sangat kecil) berdasarkan pengaruh faktor tersebut. Rating ancaman dan kelemahan diberi nilai 1 (jika nilai kelemahan/ancamannya sedikit) sampai dengan 4 (jika nilai kelemahan/ancamannya sangat besar). Kalikan bobot dengan rating untuk memperoleh skor pada masing-masing faktor. Pembobotan dan penskoringan ini dilakukan untuk mengetahui kelayakan pengembangan objek wisata Lembah Harau pada diagram analisis SWOT (Freddy Rangkuti: 2014). 


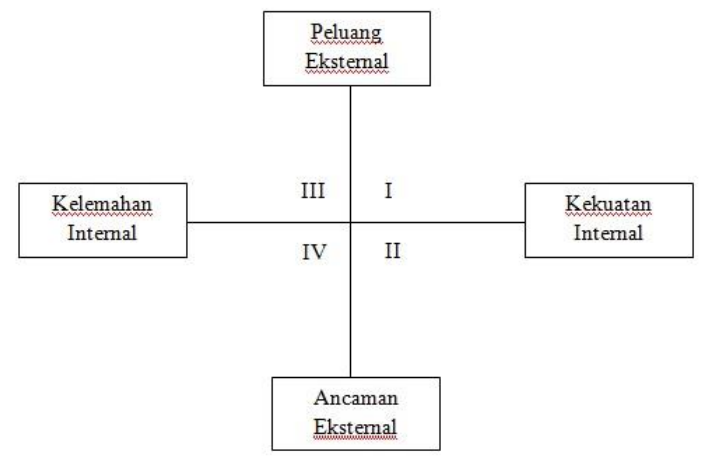

Gambar 1. Diagram SWOT
Tabel 2. Rumusan Strategi SWOT

\begin{tabular}{|c|l|c|}
\hline Internal & Strenghts (S) / Kekuatan & $\begin{array}{c}\text { Weaknesses (w) / } \\
\text { Kelemahan }\end{array}$ \\
\hline $\begin{array}{c}\text { Opportunies (O) / } \\
\text { Peluang }\end{array}$ & $\begin{array}{l}\text { Strategi SO } \\
\text { menggungakan kekuatan } \\
\text { untuk memanfaatkan } \\
\text { peluang. }\end{array}$ & $\begin{array}{l}\text { Strategi WO } \\
\text { Strategi yang } \\
\text { meminimalkankelemahan } \\
\text { untuk memanfaatkan } \\
\text { peluang. }\end{array}$ \\
\hline Treaths (T)/ Ancaman & $\begin{array}{l}\text { Strategi ST } \\
\text { Strategi yang } \\
\text { menggunakan kekuatan } \\
\text { untuk mengatasi ancaman }\end{array}$ & $\begin{array}{l}\text { Strategi WT } \\
\text { Strategi yang } \\
\text { meminimalkankelemahan } \\
\text { dan menghindari ancaman }\end{array}$ \\
\hline
\end{tabular}

Dari penggabungan analisis SWOT dan AHP objek wisata Lembah Harau dapat dirumuskan dalam bentuk tabel strategi SWOT.

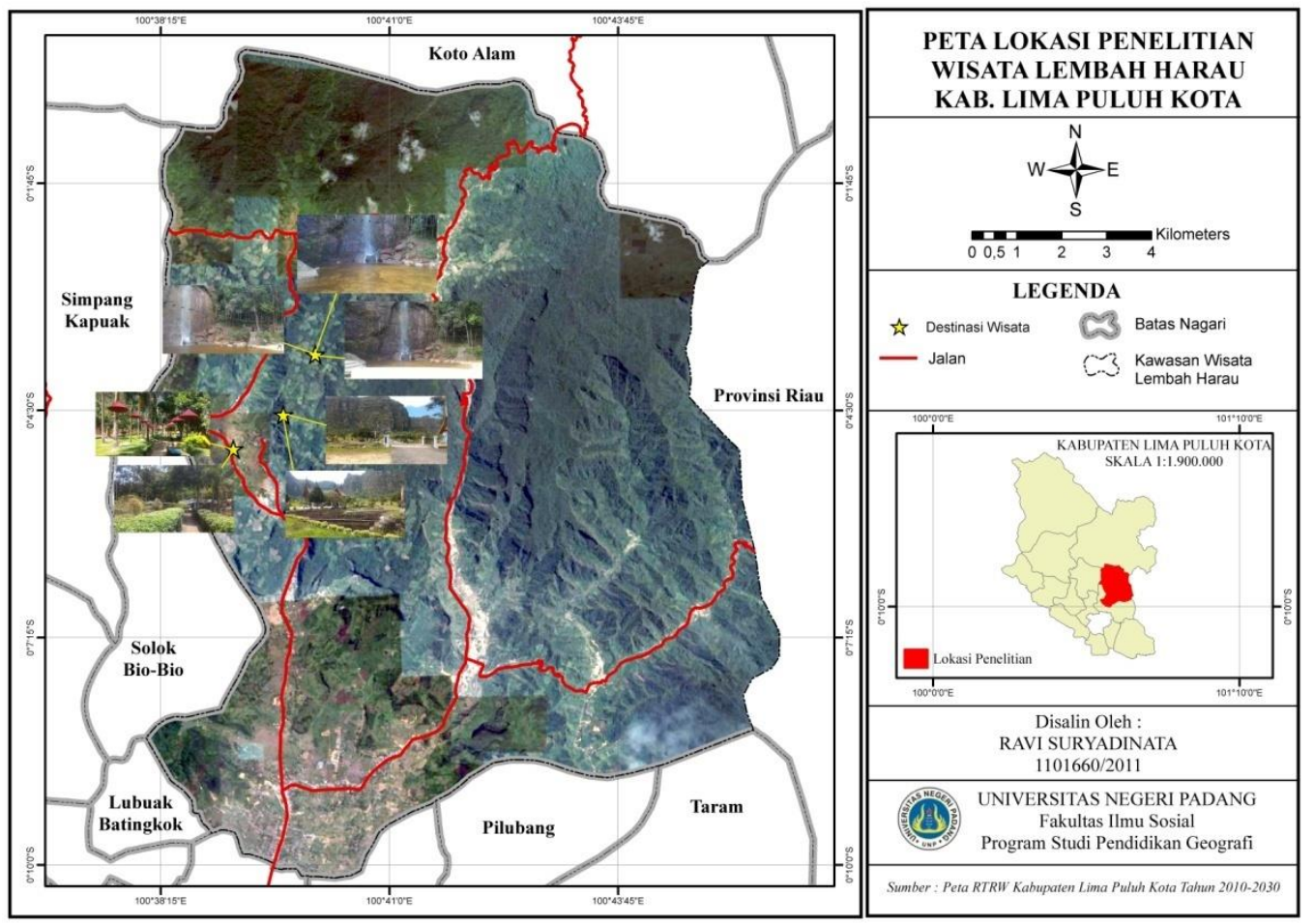

\section{HASIL PENELITIAN}

\section{Hasil Penilaian Objek Wisata Lembah Harau}

Hasil analisis objek wisata Lembah Harau Kabupaten Lima Puluh Kota didasarkan pada penilaian para pakar atau yang menekuni bidang kajian wisata Lembah Harau.

a. Kekuatan (Strenght)
Pada faktor kekuatan terdapat enam faktor yang mempengaruhi pengembangan objek wista Lembah Harau, yaitu ketersediaan sumber daya manusia yang kompeten, objek wisata yang menarik, masyarakat yang ramah dan terbuka, memiliki atraksi alam dan buatan, kondisi 
jalan menuju objek wisata tergolong baik dan udara yang sejuk.

Hasil analisis menunjukkan faktor kekuatan yang menjadi prioritas untuk pengembangan objek wisata Lembah Harau adalah objek wisatanya yang menarik. Hasil tersebut menunjukkan bahwa kekuatan objek wisata Lembah Harau diprioritaskan dari segi objek wisatanya yang menarik sehingga faktor ini memungkinkan adanya pengembangan pada objek wisata Lembah Harau.

b. Faktor Kelemahan (Weakness)

Pada faktor klemahan terdapat enam faktor yang mempengaruhi pengembangan objek wista Lembah Harau, yaitu akses masuk dan keluar hanya terdapat 1 jalur, jalan antar objek wisata yang tergolong kecil atau sempit dan tidak memiliki bahu jalan, jarak antar objek wisata yang terlalu jauh, informasi, komunikasi dan promosi yang lemah, banyak tempat tersembunyi untuk melakukan hal-hal yang negatif dan kuliner khas Kabupaten Lima Puluh Kota yang kurang ditonjolkan.

Hasil analisis menunjukkan faktor kelemahan yang menjadi prioritas untuk diatasi dalam pengembangan objek wisata Lembah Harau adalah banyak tempat tersembunyi untuk melakukan halhal negatif. Hasil tersebut menunjukkan bahwa objek wisata Lembah Harau memiliki kelemahan yang menjadi prioritas untuk diatasi dari segi tempat-tempat yang tersembunyi agar pengunjung maupun warga setempat tidak melakukan hal-hal yang negatif, sehingga faktor ini tidak memungkinkan adanya kelemahan yang dapat menjatuhkan nama baik atau menghambat pengembangan pada objek wisata.

c. Faktor Peluang (Opportunity)

Pada faktor peluang terdapat enam faktor yang mempengaruhi pengembangan objek wista Lembah Harau, yaitu meningkatkan PAD Kabupaten Lima Puluh Kota, menggerakkan sektor perekonomian masyarakat, munculnya kuliner khas Kabupaten Lima Puluh Kota, meningkatnya pelayanan untuk masyarakat yang diperoleh dari sumber pendapatan kegiatan pariwisata, meningkatnya eksistensi Kabupaten Lima Puluh Kota dan dapat mengembangkan atraksi yang berkaitan dengan alam.

Hasil analisis menunjukkan faktor peluang yang menjadi prioritas untuk pengembangan objek wisata Lembah Harau adalah menggerakkan sektor perekonomian masyarakat.

d. Faktor Ancaman (Threat)

Pada faktor ancaman terdapat enam faktor yang mempengaruhi pengembangan objek wista Lembah Harau, yaitu tidak terkendalinya kelestarian lingkungan objek wista sehingga menurunkan minat wisatawan, perubahan budaya seperti hilangnya kuliner khas Kabupaten Lima Puluh Kota karena masuknya makanan asing, persaingan antar objek wisata, ketidakstabilan ekonomi akibat kondisi pariwisata yang fluktuatif, pembangunan 
pariwisata yang tidak terkontrol dengan baik yang mengganggu kenyamanan dan merusak lingkungan, serta wisatawan lebih memilih membeli barang atau memakai jasa usaha yang dikelola dari luar sehingga menimbulkan kebocoran ekonomi.

Hasil analisis menunjukkan faktor ancaman yang menjadi prioritas untuk dicegah dalam pengembangan objek wisata Lembah Harau adalah ketidakstabilan ekonomi akibat kondisi pariwisata yang fluktuatif. Hal tersebut dapat menurunkan pemasukan objek wisata Lembah Harau.

Dari faktor-faktor hasil analisis SWOT, penilaian pembobotan didapat melalui AHP dan rating faktor-faktor analisi SWOT didapat dari penilaian para pakar pariwisata dengan skala 1-4.

Faktor internal dalam pengembangan objek wisata Lembah Harau bernialai positif yaitu 0,28 dan faktor eksternal juga bernilai positif yaitu 0,382 . Hal ini meninjukkan bahwa faktor kekuatan dan faktor peluang memiliki nilai yang lebih besar dalam kelayakan pengmbangan objek wisata Lembah Harau.

\section{Pembahasan}

Menurut Suwantoro (2004:19), Unsur pokok yang harus mendapat perhatian guna menunjang pengembangan pariwisata di daerah tujuan wisata yang menyangkut pada perencanaan, pelaksanaan pembangunan, dan pengembangannya.

Hasil analisis pada kelayakan pengembangan objek wisata Lembah Harau yang dikaji melalui analisis
SWOT dan dipresentasikan melalui AHP menunjukkan faktor internal dalam pengembangan objek wisata Lembah Harau bernilai positif yaitu 0,28 dan faktor eksternal juga bernilai positif yaitu 0,382 .

Nilai tersebut menunjukkan bahwa kelayakan pengembangan objek wisata Lembah Harau berada pada kuadran 1 yang artinya adalah objek wisata Lembah Harau dari segi pengembangannya sangat menguntungkan, yaitu memiliki kekuatan dan peluang.

$$
\text { Freddy Rangkuti }
$$
mengemukakan bahwa analisis SWOT merupakan analisis yang tepat untuk digunakan dalam mengkaji pengembangan objek wisata karena analisis SWOT lebih menitik beratkan kepada aspek penting dalam suatu pengembangan objek yang dikaji meliputi kekuatan, kelemahan, peluang, dan ancaman. Beberapa aspek analisis SWOT yang telah dikaji, pengembangan objek wisata Lembah Harau memiliki faktor kekuatan dan peluang lebih dominan dibandingkan dengan faktor kelemahan dan ancaman. Dari hasil perhitungan dengan menggunakan ketentuan Skala Saaty faktor kekuatan yang perlu diprioritaskan dalam pengembangan objek wisata Lembah Harau adalah daya tarik dari objek wisatanya yang memperlihatkan sisi keindahan alam dan didukung dengan wisata buatan, sedangkan dari segi kelemahan dan ancamannya yang menjadi prioritas adalah banyaknya tempat-tempat tersembunyi yang dikhawatirkan akan dimanfaatkan untuk hal-hal yang 
negatif atau prilaku asusila oleh pengunjung maupun warga setempat, yang terakhir adalah faktor yang berpeluang untuk menggerakkan sektor perekonomian masyarakat yang menjadikannya sebagai prioritas.

Untuk itu perlu adanya inovasi dalam pengembangan objek wisata Lembah Harau yang dirumuskan menggunakan strategi SWOT.

a. Strategi SO

Memanfaatkan objek wisatanya yang menarik untuk menggerakkan sektor perekonomian masyarakat, yaitu dengan cara memperbaharui dan menempatkan jenis-jenis hewan dikandang yang sudah disediakan serta menyediakan makanan hewan untuk wisatawan agar pengunjung dapat berinteraksi langsung dengan hewan, menambah aneka tanaman anggrek, melakukan pertukaran air secara berkala serta membangun pondasi di kolam yang terdapat di taman, membuat aliran air pembuangan disekitar taman agar air tidak tergenang pada saat terjadi hujan, menambah fasilitas tiolet dan arena baermain untuk anak-anak serta merawat kebersihan dan keindahan yang berlokasi di Aka Barayun. Pada kawasan Sarasah Bunta masih perlu penambahan tempat duduk untuk bersantai, penataan dan renofasi warungwarung yang masih tebuat dari kayu, pengelolaan sampah yang perlu ditanggulangi dengan menambahkan tempat sampah, terutama pada jalan, kali dan arena bermain disekitar air terjun, meningkatkan informasi, komunikasi dan promosi dengan cara mengadakan book travel, event yang berkaitan dengan alam atau budaya setempat dan mengadakan wisata kuliner sekali sebulan atau sekali seminggu.

b. Strategi WO

Mengatasi tempat-tempat tersembunyi untuk meminimalisir keadaan yang dikhawatirkan akan dimanfaatakan untuk hal-hal yang negatif agar sektor perekonomian masyarakat dapat ditingkatkan, yitu dengan cara membuka jalur ketempat-tempat yang tinggi, seperti di daerah perbukitan dan di tempattampat yang memiliki banyak pepohonan untuk menikmati pemandangan atau panorama bagi wisatawan dan membangun fasilitas warung untuk berdagang agar wisatawan bisa jajan.

c. Strategi ST

Menggunakan objek wisata yang menarik untuk mengatasi ketidakstabilan ekonomi akibat kondisi pariwisata yang fluktuatif, yaitu dengan cara menggelar eventevent dengan memanfaatkan potensi wisata Lembah Harau guna menggencarkan promosi wisata agar minat wisatawan untuk berkunjung semakin meningkat.

d. Strategi WT

Meminimalisir tempat-tempat tersembunyi untuk mengatasi keadaan yang dikhawatirkan akan dimanfaatakan untuk hal-hal yang negatif sehingga ketidakstabilan ekonomi akibat kondisi pariwisata yang fluktuatif dapat teratasi, yaitu dengan cara menempatkan petugas keamanan diberbagai tempat, 
terutama ditempat objek wisata yang ramai dikunjungi wisatawan dan disepanjang jalan antar objek wisata dititik-titik tertentu dengan membangun pos-pos keamanan demi kenyamanan dan kelestarian wisata Lembah Harau.

\section{PENUTUP}

\section{Kesimpulan}

Berdasarkan hasil penelitian dan pembahasan tentang pengembangan objek wisata Lembah Harau dapat disimpulakan bahwa faktor kekuatan yang menjadi prioritas dalam pengembangan objek wisata Lembah Harau adalah menambah daya tarik wisata, faktor kelemahan yang menjadi prioritas dalam pengembangan wisata Lembah Harau adalah mengatasi tempat-tempat tersembunyi yang dikhawatirkan akan digunakan untuk hal-hal yang negatif dari warga setempat maupun dari pengunjung, faktor peluang yang menjadi prioritas dalam pengembangan wisata Lembah Harau adalah menggerakkan sektor perekonomian masyarakat dan faktor ancaman yang menjadi prioritas dalam pengembangan wisata Lembah Harau adalah mengantisipasi dan meminimalisir prilaku asusila antar muda-mudi.

Pengembangan wisata Lembah Harau dilihat dari hasil analisis SWOT dan AHP yang disajikan dalam diagram SWOT menunjukkan bahwa wisata Lmbah Harau berada pada kuadran 1 yang berarti objek wisata Lembah Harau layak untuk dikembangkan karena objek wisata Lembah Harau memiliki faktor kekuatan dan peluang yang lebih dominan dibandingkan dengan faktor kelemahan dan ancaman.

Dengan memanfaatkan faktor kekuatan dan peluang yang sudah memiliki prioritas untuk dikembangkan diharapkan agar dapat secara bersamaan mengatasi/meminimalisir faktor kelemahan dan ancaman yang sudah menjadi prioritas untuk diatasi/diminimalisir, yaitu dengan memanfaatkan objek wisatanya yang menarik untuk menggerakkan sektor perekonomian masyarakat, mengatasi tempat-tempat tersembunyi untuk meminimalisir keadaan tempat-tempat yang dikhawatirkan akan dimanfaatakan untuk hal-hal yang negatif agar sektor perekonomian masyarakat dapat lebih ditingkatkan, menggunakan objek wisata yang menarik untuk meminimalisir atau mengatasi perilaku asusila antar muda-mudi yang pernah terjadi dan meminimalisir tempattempat tersembunyi untuk mengatasi keadaan yang dikhawatirkan akan dimanfaatakan untuk hal-hal yang negatif, terutama untuk perilaku asusila antar muda-mudi yang pernah terjadi.

\section{Saran}

Setelah melakukan penelitian, pembahasan dan merumuskan kesimpulan dari hasil penelitian, peneliti memberikan beberapa saran yang berkaitan dengan penelitian yang telah dilakukan untuk dijadikan masukan dan bahan pertimbangan yang berguna bagi pihak-pihak yang berkepentingan.

Perlu adanya integrasi antara pemerintah dan masyarakat setempat dalam mengembangkan objek-objek wisata yang terdapat pada wisata 
Lembah Harau sesuai dengan sapta pesona dalam pariwisata.

Pengembangan wisata Lembah Harau dapat dilakukan melalui inovasiinovasi dalam menarik wisatawan untuk berkunjung ke wisata Lembah Harau seperti membuat book travel, pamflet, penataan warung-warung, menyajikan kuliner khas setempat dan membuat event, baik yang berkaitan dengan alam maupun budaya setempat.

\section{DAFTAR RUJUKAN}

Kodhyat. 1996. Sejarah Pariwisata dan Perkembangannya $d i$ Indonesia.Jakarta. PT Grasindo.

Moleong, Lexy J. 2002. Metodologi Penelitian Kualitatif. Bandung: Remaja Rosda Karya

Rangkuti, Freddy. 2014. Analisis SWOT. Jakarta: Gramedia Pustaka Utama.
Saaty, Thomas L. 1993. Pengambilan Keputusan Bagi Para Pemimpin, Proses Hirarki Analitik untuk Pengambilan Keputusan dalam Situasi yang Kompleks. Setiono L, penerjemah; Peniwati K, editor. Jakarta: PT.Pustaka Binaman Pressindo. Terjemahan dari: Decision Making for Leaders The Analytical Hierarchy Process for Decisions in Complex World.

Sugiyono . 2012. Metode Penelitian Kuantitatif, Kualitatif dan $R \& D$. Bandung: Alfabeta.

Suwantoro, Gamal. 2004. Dasar-dasar Pariwisata. Yogyakarta: Andi.

Yoeti, Oka.A.1996. Pengantar Ilmu Pariwisata. Angkasa: Bandung. 